\title{
Current trends of antibiotic resistance among human skin infections causing bacteria; a cross- sectional study
}

\begin{abstract}
Objectives: To determine the current status of skin infections causing bacteria and their pattern of resistance to widely used antibiotics among the physician referred patients in district Peshawar, Pakistan.

Materials and methods: A cross-sectional study of 164 pus samples from diseased patients, referred by physicians was done for a period from February 2020 to January 2021 at Department of Microbiology, Complex medical laboratory and Research center, Peshawar, Pakistan.

Results: The bacterial growth were obtained in 88 pus samples. Among these isolated bacterial species Escherichia coli was the most prevalent pathogen, present in (46\%), Staphylococcus aureus (39\%), Proteus species (11\%), Klebseilla species (2\%) and Pseudomonas aerugenosa (2\%), respectively. Among the tested antibiotics resistance wise E.coli was highly resistance to Ampicillin (92.5\%), S. Aureus to Levofloxacin (91.1\%), Proteus spp. to Doxycycline (90\%), Klebsiella spp. to Meropenem (100\%), Amoxicillin $(100 \%)$ and $P$. aeruginosato Aztreonam (100\%), Doxycycline (100\%), respectively. Sensitivity wise E.coli was highly sensitive to Amikacin (90\%), S. aureus to Meropenem (91.1\%) and Doxycycline (91.1\%),Proteus spp. to Meropenem (100\%), Klebsiella spp. to Ciprofloxacin (100\%), Cefotaxime (100\%), Aztreonam (100\%) and Doxycycline $(100 \%)$, P. aeruginosa to Amikacin (100\%), Meropenem(100\%), Ciprofloxacin (100\%), Gentamicin $(100 \%)$, Cefotaxime $(100 \%)$, Ceftriaxone $(100 \%)$, Ampicillin $(100 \%)$ and Cefotaxime $(100 \%)$, respectively.

Conclusion: The most prevalent skin infections causing bacteria was E.coli, followed by S. aureus, Proteus spp., Klebseilla spp. and P. aerugenosa, respectively. The antibiogram provides adequate knowledge of effective therapeutic agents for the treatment strategies of skin infections.
\end{abstract}

Keywords: skin infections, pus samples, antibiotic sensitivity
Volume 5 Issue 4 - 202I

\author{
Muddasir Khan,' Syed Hussain Shah, ${ }^{2}$ \\ Muhammad Salman,' Ziaur Rahman, ${ }^{3}$ Arshad \\ Hussain, ${ }^{3}$ Abdullah,' Muhammad Awais, \\ Muhammad Asfandyar Khan ${ }^{4}$ \\ 'Department of Health and Biological Sciences, Abasyn \\ University Peshawar, Pakistan \\ ${ }^{2}$ Alliance Pharmaceutical Industry, Pakistan \\ ${ }^{3}$ Food Technology Centre, PCSIR Laboratories Complex, \\ Pakistan \\ ${ }^{4}$ Department of Biosciences, COMSATS University Islamabad, \\ Pakistan
}

Correspondence: Muddasir Khan, Department of Health and Biological Sciences, Abasyn University Peshawar, Pakistan, Emailmk03025678947@gmail.com, muddasir.khan0302@gmail.com

Received: July 06, 202I | Published: July 22, 2021

\section{Introduction}

Microbial pathogens caused skin infection in human. These infections are most likely to be caused after or during burn injuries, trauma and surgical procedures. These types of infections lead to cause the production of dead WBCs, which appear in the form of white to yellow fluid, known as pus. ${ }^{1,2}$ Globally, high rate of morbidity are caused by wound infections and especially high rate of infections present in hospitalized patients. Human skin infections are caused by both aerobic and anaerobic bacteria. ${ }^{3}$ The emergence of new antibiotics resistance strains of pathogenic bacteria are associated with the misuse of antibiotics and public awareness. The multidrug-resistance bacteria are huge threats to public health from last few decades. ${ }^{4}$

The skin infections are frequently caused by Gram positive bacteria including; S. aureus, S. epidermidis and Gram negative bacteria including E. coli, Pseudomonas spp., Klebsiella spp., Acinetobacter spp., Citrobacter spp., Enterobacter spp., respectively. ${ }^{5}$ However, the causative agent and antibiotics resistance pattern are very from place to place. Adequate, knowledge of the microbial pathogen potential and understanding of the therapeutic agent shall be required for an effective microbial infection agent to be selected. ${ }^{6}$

Therefore, the aim of the current study is to evaluate the current status of skin infections causing bacteria and their pattern of resistance to widely used antibiotics among the physician referred patients in district Peshawar, Pakistan.This study provides adequate knowledge of potential microbial pathogen and effective therapeutic agents of skin infections in Pakistan.

\section{Materials and methods}

\section{Ethical approval}

The ethical committees of the Complex Medical Laboratory and Research Center in Peshawar, as well as the ethical committees of Abasyn University in Peshawar, Pakistan, gave approval to this study.

\section{Samples collection}

A cross-sectional study of 164 pus samples from diseased patients, referred by physicians was done for a period from February 2020 to January 2021 at Department of Microbiology, Complex medical laboratory and Research center, Peshawar, Pakistan. The samples were collected through sterile stick swabs and labeled.

\section{Isolation of pathogens}

The labeled samples were aseptically inoculated on Blood agar media and MacConkey Agar media. All labeled plates were incubated aerobically at $37^{\circ} \mathrm{C}$ for 24 hours. The positive samples growth was 
observed and processed for Gram staining. Identification of pathogens were done through biochemical tests including; Oxidase test, Catalase test, Urease test, Utilization test, Voges Proskauer test, Citrate, Indole test, Methyl red test, H2S test, and Motility from pure isolated colony.

\section{Antibiotic susceptibility assay}

In accordance with the Clinical and Laboratory Standards Institute (CLSI) guidelines 2019, Kirby Bauer's disc diffusion technique was used to test the antibiogram of the isolates. To test antimicrobial resistance to isolates, commercially available antibiotic discs (Oxoid, Ltd, England) were used. For the disc diffusion test, the concentration of applied drugs was Amikacin (AK) 30 $\mu \mathrm{g}$, Meropenem (MEM) $10 \mu \mathrm{g}$, Levofloxacin (LEV) $5 \mu \mathrm{g}$, Ciprofloxacin (CIP) $5 \mu \mathrm{g}$, Gentamicin

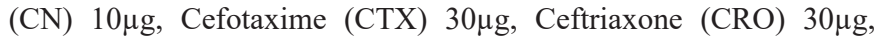

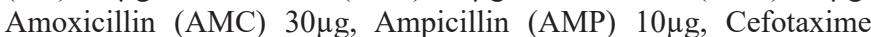
(CTX) $30 \mu \mathrm{g}$, Aztreonam (ATM) 30 $\mathrm{g}$ andDoxycycline (DXT) $30 \mu \mathrm{g}$. In order to grow fresh culture, an inoculum of $2 \mathrm{ml}$ Muller Hinton broth was prepared and incubated at $37^{\circ} \mathrm{C}$ for 4 hours. The new culture was then applied to the standard McFarland 0.5. A sterile cotton swab was immersed in the suspension and striped on the surface of Muller Hinton agar plate. The plate was then dried for a few minutes at room temperature. Antibiotic discs were aseptically placed on the agar surface with sterile forceps, and plates were incubated at $37^{\circ} \mathrm{C}$ for 24 hours. The resistance and sensitivity pattern were determined after incubation. ${ }^{?}$

\section{Results}

Out of 164 pus samples from skin disease patients referred by physicians, 88 samples showed bacterial growth and 76 samples were negative for growth. Based on Gram staining and through biochemical tests the bacterial isolates were assigned to five bacterial species. Among these isolated bacterial species E.coli was the most prevelent pathogen, present $46 \%$. The second prevelent pathogen was $S$. aureus (39\%), followed by Proteus spp. (11\%), Klebseilla spp. (2\%) and P. aerugenosa $(2 \%)$, respectively (Figure 1).
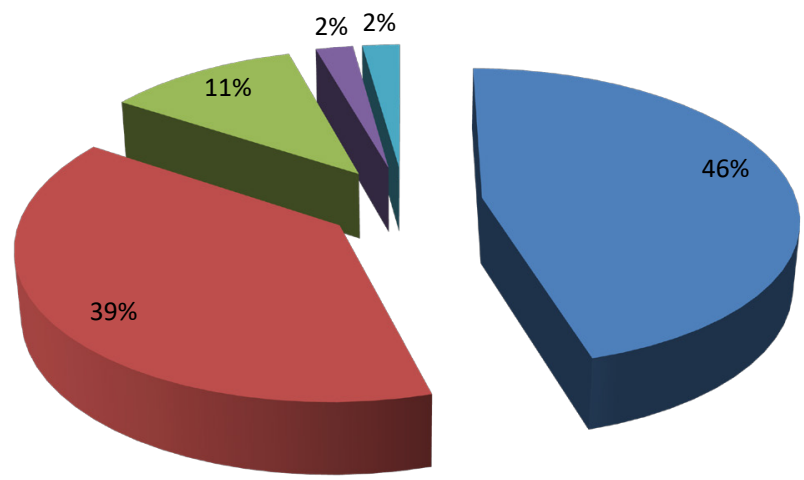

Escherichia coli

- Staphylococcus aureus

- Proteus spp.

- Klebsiella spp.

Pseudomonas aeruginosa

\begin{tabular}{c|c|c|c|c|c|c}
\hline $\begin{array}{c}\text { Isolated } \\
\text { Pathogens }\end{array}$ & $\begin{array}{c}\text { Escherichia } \\
\text { coli }\end{array}$ & $\begin{array}{c}\text { Staphylococcus } \\
\text { aureus }\end{array}$ & $\begin{array}{c}\text { Proteus } \\
\text { spp. }\end{array}$ & $\begin{array}{c}\text { Klebsiella } \\
\text { spp. }\end{array}$ & $\begin{array}{c}\text { Pseudomonas } \\
\text { aeruginosa }\end{array}$ & Total (\%) \\
\hline $\begin{array}{c}\text { Number } \\
(\%)\end{array}$ & $40(46 \%)$ & $34(39 \%)$ & $10(11 \%)$ & $2(2 \%)$ & $2(2 \%)$ & $88(100 \%)$ \\
\hline
\end{tabular}

Figure I Overall distribution of skin infections using bacteria.

Antibiotics resistance pattern of the present study shows, among the tested antibiotics E.coli revealed high resistance to Ampicillin (92.5\%) and highly sensitive to Amikacin (90\%). S. aureus shows high resistance to Levofloxacin (91.1\%), highly sensitive to Meropenem (91.1\%) and Doxycycline (91.1\%). Proteus spp. shows high resistance to Doxycycline (90\%) and highly sensitive to Meropenem (100\%). Klebsiella spp. shows high resistance to Meropenem (100\%),
Amoxicillin (100\%), highly sensitive to Ciprofloxacin (100\%), Cefotaxime (100\%), Aztreonam (100\%) and Doxycycline (100\%). P. aeruginosa shows high resistance to Aztreonam (100\%), Doxycycline (100\%), highly sensitive to Amikacin (100\%), Meropenem (100\%), Ciprofloxacin (100\%), Gentamicin $(100 \%)$, Cefotaxime $(100 \%)$, Ceftriaxone (100\%), Ampicillin (100\%) and Cefotaxime $(100 \%)$, respectively (Table 1).

Table I Antibiotics sensitivity and resistance pattern of skin infections causing bacteria

\begin{tabular}{|c|c|c|c|c|c|c|c|c|c|c|}
\hline \multirow{2}{*}{$\begin{array}{l}\text { Antibiotics } \\
\text { Disc }\end{array}$} & \multicolumn{2}{|c|}{ E. coli $(n=40)$} & \multicolumn{2}{|c|}{ S. aureus $(n=34)$} & \multicolumn{2}{|c|}{ Proteus spp. $(n=10)$} & \multicolumn{2}{|c|}{ Klebsiella spp. $(\mathrm{n}=02)$} & \multicolumn{2}{|c|}{$P$. aeruginosa $(\mathrm{n}=02)$} \\
\hline & S (\%) & $\mathbf{R}(\%)$ & S (\%) & $\mathbf{R}(\%)$ & S (\%) & R (\%) & S (\%) & $\mathbf{R}(\%)$ & $\mathbf{S}(\%)$ & R (\%) \\
\hline $\begin{array}{l}\text { Amikacin (AK) } \\
30 \mu \mathrm{g}\end{array}$ & $36(90 \%)$ & $4(10 \%)$ & $30(88.2 \%)$ & 4 (II.7\%) & $8(80 \%)$ & $2(20 \%)$ & I (50\%) & I (50\%) & $2(100 \%)$ & $0(0 \%)$ \\
\hline $\begin{array}{l}\text { Meropenem } \\
\text { (MEM) I0 10g }\end{array}$ & $26(65 \%)$ & 14 (35\%) & 31 (9l.1\%) & $3(8.8 \%)$ & $10(100 \%)$ & $0(0 \%)$ & $0(0 \%)$ & $2(100 \%)$ & $2(100 \%)$ & $0(0 \%)$ \\
\hline $\begin{array}{l}\text { Levofloxacin } \\
\text { (LEV) } 5 \mu g\end{array}$ & $8(20 \%)$ & $32(80 \%)$ & $3(8.8 \%)$ & 31 (91.1\%) & $5(50 \%)$ & $5(50 \%)$ & I (50\%) & I (50\%) & I (50\%) & I (50\%) \\
\hline
\end{tabular}


Table Continued..

\begin{tabular}{|c|c|c|c|c|c|c|c|c|c|c|}
\hline \multirow{2}{*}{$\begin{array}{l}\text { Antibiotics } \\
\text { Disc }\end{array}$} & \multicolumn{2}{|c|}{ E. coli $(n=40)$} & \multicolumn{2}{|c|}{ S. aureus $(n=34)$} & \multicolumn{2}{|c|}{ Proteus spp. $(\mathrm{n}=10)$} & \multicolumn{2}{|c|}{ Klebsiella spp. $(\mathrm{n}=02)$} & \multicolumn{2}{|c|}{$P$ aeruginosa $(\mathrm{n}=02)$} \\
\hline & $\mathbf{S}(\%)$ & R (\%) & S (\%) & R (\%) & $\mathbf{S}(\%)$ & R (\%) & S (\%) & $\mathbf{R}(\%)$ & $\mathbf{S}(\%)$ & R (\%) \\
\hline $\begin{array}{l}\text { Ciprofloxacin } \\
\text { (CIP) } 5 \mu g\end{array}$ & $6(15 \%)$ & $34(75 \%)$ & $4(11.7 \%)$ & $30(88.2 \%)$ & $8(80 \%)$ & $2(20 \%)$ & $2(100 \%)$ & $0(0 \%)$ & $2(100 \%)$ & $0(0 \%)$ \\
\hline $\begin{array}{l}\text { Gentamicin } \\
(\mathrm{CN}) 10 \mu \mathrm{g}\end{array}$ & $24(60 \%)$ & $16(40 \%)$ & $21(61.7 \%)$ & $13(38.2 \%)$ & $9(90 \%)$ & I (I0\%) & I (50\%) & I (50\%) & $2(100 \%)$ & $0(0 \%)$ \\
\hline 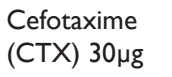 & $12(30 \%)$ & $28(70 \%)$ & $20(58.8 \%)$ & $14(4 \mid .1 \%)$ & $7(70 \%)$ & $3(30 \%)$ & $2(100 \%)$ & $0(0 \%)$ & $2(100 \%)$ & $0(0 \%)$ \\
\hline $\begin{array}{l}\text { Ceftriaxone } \\
(\mathrm{CRO}) 30 \mu \mathrm{g}\end{array}$ & $19(47.5 \%)$ & $21(52.5 \%)$ & $23(67.6 \%)$ & II (32.3\%) & $9(90 \%)$ & I (I0\%) & I (50\%) & I (50\%) & $2(100 \%)$ & $0(0 \%)$ \\
\hline $\begin{array}{l}\text { Amoxicillin } \\
(\mathrm{AMC}) 30 \mu \mathrm{g}\end{array}$ & $5(12.5 \%)$ & $35(87.5 \%)$ & $20(58.8 \%)$ & $14(4 \mid .1 \%)$ & $9(90 \%)$ & I (I0\%) & $0(0 \%)$ & $2(100 \%)$ & I (50\%) & I (50\%) \\
\hline 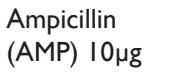 & $3(7.5 \%)$ & 37 (92.5\%) & 21 (6I.7\%) & I 3 (38.2\%) & $3(30 \%)$ & 7 (70\%) & I (50\%) & I (50\%) & 2 (100\%) & $0(0 \%)$ \\
\hline 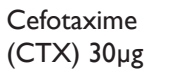 & I I (27.5\%) & $29(72.5 \%)$ & I4 (4I. I\%) & $20(58.8 \%)$ & $8(80 \%)$ & $2(20 \%)$ & I (50\%) & I (50\%) & $2(100 \%)$ & $0(0 \%)$ \\
\hline 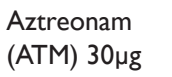 & $6(15 \%)$ & 34 (75\%) & 17 (50\%) & 17 (50\%) & 7 (70\%) & $3(30 \%)$ & $2(100 \%)$ & $0(0 \%)$ & $0(0 \%)$ & $2(100 \%)$ \\
\hline $\begin{array}{l}\text { Doxycycline } \\
(\mathrm{DXT}) 30 \mu \mathrm{g}\end{array}$ & $16(40 \%)$ & $24(60 \%)$ & 31 (9l.I\%) & $3(8.8 \%)$ & I (I0\%) & $9(90 \%)$ & $2(100 \%)$ & $0(0 \%)$ & $0(0 \%)$ & $2(100 \%)$ \\
\hline
\end{tabular}

\section{Discussion}

The skin infections are frequently caused by Gram positive bacteria and Gram negative bacteria. ${ }^{5}$ In the present study, the most prevalent skin infections causing bacteria was E.coli (46\%), followed by $S$. aureus (39\%), Proteus spp. (11\%), Klebseilla spp. (2\%) and $P$. aerugenosa (2\%), respectively. The present study is an agreement with the previous finding of Javeed et al. ${ }^{8}$ who reported, the most prevlent pathogen in pus samples was E.coli. The obtained results is also similar to another reported study, according to his study the E.coli is the most prevelent pathogen among the pus samples and second pathogen is $S$. aureus. ${ }^{7}$ However, the results of another study shows that $P$. aerugenosa is abundent among the samples abtained from burn wound patients, the current finding is contrast to this study. Our study is also contrast to the Muluye et al. ${ }^{9}$ and Jamatia et al. ${ }^{5}$, who reported S.aureus as aboundent pathogen among the pus samples.

The current study result shows, E.coli revealed high resistance to Ampicillin (92.5\%) and highly sensitive to Amikacin (90\%), the Javeed et al. ${ }^{8}$ reported Ampicillin (90.1\%) resistance of E.coli, agreement with the current finding.According to the previous study in Pakistan, S. aureus shows high resistance to Doxycycline, Levofloxacin, Oflaxacin and Ciprofloxacin, while showing low resistance to Meropenum and Amikacin. ${ }^{10}$ In current study, S. aureus shows high resistance to Levofloxacin $(91.1 \%)$, highly sensitive to Meropenem (91.1\%) and Doxycycline (91.1\%). Our study is similar to the previous findings, but $S$. aureus sensitivity to Doxycycline (91.1\%) is contrast to the previous findings. According to the present study, Proteus spp. shows high resistance to Doxycycline (90\%) and highly sensitive to Meropenem (100\%). Klebsiella spp. shows high resistance to Meropenem (100\%), Amoxicillin (100\%), highly sensitive to Ciprofloxacin $(100 \%)$, Cefotaxime $(100 \%)$, Aztreonam (100\%) and Doxycycline (100\%). P. aeruginosa shows high resistance to Aztreonam (100\%), Doxycycline (100\%), highly sensitive to Amikacin (100\%), Meropenem (100\%), Ciprofloxacin (100\%), Gentamicin (100\%), Cefotaxime (100\%), Ceftriaxone $(100 \%)$, Ampicillin $(100 \%)$ and Cefotaxime (100\%), respectively. These current study finding supported by the previous studies of Khan et al. ${ }^{11}$ in Peshawar Pakistan, Hubab et al. ${ }^{12}$ in Peshawar Pakistan, Rashid et al. ${ }^{13}$ in Faisalabad Pakistan.

\section{Conclusion}

The most prevalent skin infections causing bacteria was E.coli, followed by S. aureus, Proteus spp., Klebseilla spp. and P. aerugenosa, respectively. This study provide current resistance status of pathogens to common antibiotics. The antibiogram of this study provides adequate knowledge of potential microbial pathogen and effective therapeutic agents for the treatment strategies of skin infections.

\section{Conflicts of interest}

The authors declare no conflict of interest.

\section{Acknowledgments}

None.

\section{Funding}

None.

\section{References}

1. Cogen AL, Nizet V, Gallo RL. Skin microbiota: a source of disease or defence?. Brj dermatol. 2008;158(3):442-455.

2. Matthew S, Dryden. Complicated skin and soft tissue infection. Journal of Antimicrobial Chemotherapy. 2010; 65(3):iii35-iii44.

3. Bowler PG, Duerden BI, Armstrong DG. Wound microbiology and associated approaches to wound management. Clinical microbiology reviews. 2001;14(2):244-269.

4. Hsu LY, Apisarnthanarak A, Khan E, et al. Carbapenem- Resistant Acinetobacter baumannii and Enterobacteriaceae in South and Southeast Asia. Clin microbiol rev. 2017;30(1):1-22.

5. Jamatia A, Roy D, ShilR, et al. Bacteriological Profile and Antimicrobial Resistance Patterns Isolates in Pus Samples at Agartala Government Medical College. Asian Journal of Pharmaceutical and Clinical Research. 2017;10(1):335-337.

6. AgnihotriN, Gupta V, Joshi RM. Aerobic bacterial isolates from burn wound infections and their antibiogramsa five- year study. Burns. 2004;30(3):241-243. 
7. Trojan R, Razdan L, Singh N. Antibiotic Susceptibility Patterns of Bacterial Isolates from Pus Samples in a Tertiary Care Hospital of Punjab, India. Int J Microbiol. 2016; 4.

8. JaveedI, HafeezR, Anwar MS. Antibiobitc susceptibility pattern of bacterial isolates from patients admitted to a tertiary care hospital in Lahore.Biomedica. 2011; 27:19-23.

9. Muluye D, Wondimeneh Y, Ferede G, et al. Bacterial isolates and their antibiotic susceptibility patterns among patients with pus and/or wound discharge at Gondar university hospital. BMC Research Notes. 2014; 7:619.

10. Taj Y, Abdullah EF, Kazmi SU. Current Pattern of Antibiotic Resistance in Staphylococcus Aureus Clinical Isolates and the Emergence of Vancomycin Resistance. Journal of the College of Physicians and Surgeons Pakistan. 2010;20 (11):728-732.
11. Khan I, Sarwar N, Ahmad B, et al. Identification and Antimicrobial Susceptibility Profile of Bacterial Pathogens Isolated From Wound Infections in a Teaching Hospital, Peshawar, Pakistan. Adv. Life Sci. 2017;5(1):08-12.

12. Hubab M, Ullah O, Hayat A, et al. Antibiotic susceptibility profile of bacterial isolates from post- surgical wounds of patients in tertiary care hospitals of Peshawar, Pakistan. J Pak Med Assoc. 2018; 68(10):15171521

13. Rashid A, Saqib M, Deeba F, et al. Microbial profile of burn wound infections and their antibiotic sensitivity patterns at burn unit of allied hospital Faisalabad. Pak J Pharm Sci. 2019; 32:247- 254. 